\title{
Aplicação de um programa integrado de controle da leptospirose em eqüinos no Rio de Janeiro, Brasil
}

\section{Application of an integrated program of leptospirosis control in horses from Rio de Janeiro, Brazil}

\author{
Melissa Hanzen Pinna, ${ }^{*}$ Renato Varges, ${ }^{*}$ Walter Lilenbaum**
}

\begin{abstract}
Resumo
Um plantel localizado na região serrana do Rio de Janeiro com 140 éguas e oito garanhões foi estudado em março de 2006. Realizou-se sorodiagnóstico para leptospirose de todos os animais do plantel e $82(55,4 \%)$ foram soropositivos.O serovar. Bratislava foi o mais freqüente e identificado em $72(87,8 \%)$ amostras reativas. Diante dos achados, um amplo programa de controle da infecção foi elaborado, incluindo abordagens vacinais, medicamentosas e epidemiológicas. Doze meses após a implementação do programa de controle (maio de 2007) constatou-se redução no índice de abortamento de $12 \%$ para $4 \%$, morte embrionária de $10 \%$ para $2 \%$ e morte neonatal de $8 \%$ para $1 \%$, totalizando $7 \%$ de prejuízos reprodutivos, perante $30 \%$ observados antes da implementação do programa de controle. Nesta ocasião, selecionaram-se randomicamente 31 fêmeas para testagem sorológica. Onze animais $(35,48 \%)$ apresentaram sororreatividade, a maioria com baixos títulos. Em relação à distribuição do serovar infectante, sv. Bratislava foi ainda o mais freqüente. Desta forma, conclui-se que a ampla abordagem, incluindo simultaneamente a vacinação, antibioticoterapia e a administração de alguns aspectos ambientais foi imprescindível para o sucesso no controle da enfermidade neste rebanho.
\end{abstract}

Palavras-chave: leptospirose, eqüinos, controle, Bratislava.

\begin{abstract}
A flock from Rio de Janeiro with 140 mares and eight stallions was studied in March, 2006. Serodiagnosis for leptospirosis was performed in all the animals and 82 (55.4\%) were seroreactive. The serovar Bratislava was the most frequent, in $72(87.8 \%)$ of the reactive samples. Considering those findings a broad control program of the disease was applied, including vaccines, antibiotics and epidemiological measures. Twelve months after the beginning of the program (May, 2007) abortion reduced from $12 \%$ to $4 \%$, embryonic death from $10 \%$ to $2 \%$ and neonatal death from $8 \%$ to $1 \%$, with total reproductive losses decreasing from $30 \%$ to $7 \%$. In this moment, 31 mares were randomly tested and eleven (35.48\%) were seroreactive, most of them with low titres. Bratislava was still the most frequent serovar. Therefore, we conclude that the broad approach of the control program, which included vaccines, antibiotics and correction of some environmental aspects was mandatory for the efficacy of the disease control.
\end{abstract}

Keywords: leptospirosis, horse, control, Bratislava.

\section{Introdução}

A leptospirose é uma antropozoonose direta e pode acometer diversas espécies animais, inclusive a eqüina, manifestandose nos ecossistemas silvestre, urbano e rural (Vasconcellos, 2000). No Brasil, evidências da infecção, caracterizadas pela identificação de aglutininas específicas antileptospiras em eqüinos têm sido relatadas há mais de 60 anos (Correa et al., 1955), em diversos estados, como Minas Gerais (Cordeiro et al., 1974), Rio grande do Sul (Pescador et al., 2004) e Rio de Janeiro (Lilenbaum, 1998). Este último estudo, realizado em éguas com problemas reprodutivos, registrou como serovares (sv.) predominantes as amostras Icterohaemorrhagiae, Bratislava e Pomona.
As manifestações clínicas da doença variam com a espécie animal e o serovar envolvido, sendo mais freqüentemente observado na espécie eqüina, alterações na esfera reprodutiva como abortamento, natimortalidade, parição de crias debilitadas e infertilidade (Ellis et al., 1983; Vasconcellos, 2000). Além disso, pode-se identificar outras alterações clínicas, como uveíte, ceratite e icterícia (Lilenbaum, 1998) e miosites (Levett, 2001), levando à queda de performance (Vasconcellos, 2000).

Exames sorológicos mostram que a doença é de ocorrência mundial, mas o serovar predominante de $L$. interrogans em diferentes países pode variar. A prevalência de infecção leptospiral em eqüinos pelos sv. Icterohaemorrhagiae ou

* Faculdade de Castelo - FACASTELO. Rua Luiz Ceotto, 57, Castelo - ES - CEP 29360-000. melissahp@click21.com.br

** Laboratório de Bacteriologia Veterinária, Universidade Federal Fluminense. Rua Hernani Mello, 101 sala 309. CEP 214210-130. mipwalt@vm.uff.br (W. Lilenbaum); renatovarges@yahoo.com.br (R. Varges) 
Pomona é bem documentada, enquanto sv Bratislava é menos freqüentemente citado (Pinna et al., 2007). Ellis et al. (1983) sugerem que sv. Bratislava pode ser adaptado aos cavalos, mas a significância clínica da infecção por este serovar ainda não é bem esclarecida, apesar de sua seroprevalência ter sido relatada em índices de $40-70 \%$ nos rebanhos estudados na América do Norte, Austrália e Reino Unido (Heath and Johnson, 1994). No Brasil, apesar do considerável plantel de cavalos, existem poucos estudos sobre a leptospirose eqüina. Apesar de jamais ter sido isolado e tipificado no Brasil, evidência sorológica da presença do sv. Bratislava já foi relatada nos estados de São Paulo (Langoni et al., 2004) e do Rio de Janeiro, mas a correlação com os casos clínicos ainda não é bem conhecida (Lilenbaum, 1998; Pinna et al., 2007).

O controle da infecção leptospírica pode ser realizado de duas formas principais: a que objetiva a completa erradicação do agente no plantel, baseada na progressiva identificação e tratamento de portadores, e a que se propõe a controlar seus efeitos sobre os animais, baseada na vacinação dos animais e uso esporádico de antibióticos (Faine et al., 2000). Em ambas as situações, variáveis ambientais características de países tropicais muitas vezes não são devidamente levadas em conta. O presente trabalho objetivou relatar a aplicação de um programa integrado de controle da leptospirose em eqüinos.

\section{Material e métodos}

\section{Desenho do Estudo}

No primeiro momento do estudo (março de 2006), os animais foram submetidos à avaliação clínica buscando identificar quaisquer sinais sugestivos da enfermidade, com ênfase nos exames oftalmológico e reprodutivo. O histórico clínico e reprodutivo dos animais foi avaliado de acordo com a análise de fichas individuais. Amostras sanguíneas foram colhidas e testadas para detecção de anticorpos antileptospiras.

\section{Animais e propriedade}

Um plantel localizado na região serrana do Rio de Janeiro, com 140 éguas e oito garanhões foi estudado em março de 2006. A propriedade estava situada em região com constantes inundações e observou-se a presença de um lago natural, utilizado para atividades diárias de exercício dos animais. Éguas vindas de outros plantéis eram constantemente encaminhadas à fazenda para cobertura, sem a realização de quarentena ou exame sorológico prévio. No momento do primeiro exame, o plantel apresentava um alto nível de abortamentos (12\%), além da ocorrência de outros problemas reprodutivos como morte embrionária (10\%) e morte neonatal (8\%), totalizando prejuízos reprodutivos em torno de $30 \%$. Os fetos abortados apresentavam icterícia e hepatomegalia, com fígados friáveis. Uveíte também foi um achado freqüente, com 16 novos casos observados no ano anterior ao estudo.

\section{Sorologia}

Amostras sanguíneas foram colhidas de todos os animais do plantel, em tubos a vácuo por de punção na veia jugular de cada animal. Em seguida, resfriadas e transportadas até o laboratório, onde foram centrifugadas e os soros estocados em tubos Eppendorf a $-20^{\circ}$ para posterior análise. O diagnóstico sorológico para leptospirose foi realizado de acordo com a recomendação técnica da Organização Mundial de Saúde, utilizando a técnica da soroaglutinação microscópica com antígenos vivos (Lilenbaum e Santos, 1995). Utilizou-se uma coleção de antígenos pertencente ao Laboratório de Bacteriologia Veterinária do Departamento de Microbiologia e Parasitologia da Universidade Federal Fluminense, composta de 21 serovares distintos de leptospiras, representando os 18 sorogrupos conhecidos. Todas as amostras com atividade aglutinante em diluição 1:50 foram, posteriormente, testadas contra o antígeno reativo usando diluições em série de razão dois até que o título mais alto fosse obtido, a fim de identificar o serovar infectante.

\section{Programa de Controle}

Após os resultados da primeira triagem sorológica, todos os animais foram vacinados utilizando-se vacina preparada com estirpe padrão de Bratislava, adquirida junto ao banco de estirpes da EV-UFMG, inativada por formol e sem adição de fenol ou adjuvantes (IPEVE, Brasil). A vacina foi aplicada via IM e reforçada após 60 dias. Já no que diz respeito às medidas medicamentosas, todos os animais sororreativos $(\geq 200)$ do plantel foram tratados com dose única de diidroestreptomicina (25mg/kg PV), segundo recomendação internacional (Gerritsen et al., 1994; Faine et al., 2000). Os animais visitantes, que vinham ao haras para coberturas, também eram medicados no mesmo esquema terapêutico no dia de sua partida, a fim de evitar a disseminação da infecção. Importantes medidas epidemiológicas foram adotadas neste plantel: vários alagadiços foram drenados e o lago onde os animais se exercitavam foi interditado. Regiões alagadiças onde não foi possível a drenagem foram isoladas. De todos os animais ingressantes no haras exigiu-se teste sorológico negativo para leptospirose e os animais visitantes eram mantidos em regiões do haras especificamente destinadas para tal. Um ano após a aplicação de um programa de controle (maio de 2007), novas análises clínica, reprodutiva e sorológica foram realizadas, avaliando-se os resultados do programa aplicado.

\section{Resultados}

Dentre as 148 amostras testadas, 40 (27,0\%) apresentaram títulos $\geq 800$ e $42(28,4 \%)$ títulos entre 200 e 400 . Os restantes 66 animais $(44,6 \%)$ apresentaram títulos $\geq 100$. De acordo com relatos prévios para o mesmo estado (Lilenbaum, 1998), e considerando o caráter endêmico da infecção, estabeleceuse para o presente estudo o ponto de corte de 200. Desta forma, $82(55,4 \%)$ animais foram classificados como soropositivos para leptospirose.

Em relação à distribuição do serovar infectante, sv. Bratislava foi o mais freqüente, tendo sido identificado em 37 amostras com altos títulos e 35 fracamente reativos, totalizando 72 $(87,8 \%)$ amostras com títulos $\geq 200$. Os sv. Icterohaemorrhagiae e Australis também foram observados, correspondendo a seis $(7,3 \%)$ e quatro $(4,9 \%)$ amostras com títulos $\geq 200$, respectivamente (Tabela 1). 
Tabela 1: Eqüinos de propriedade do estado do Rio de janeiro, Brasil, submetidos ao teste de soroaglutinação microscópica aplicado à leptospirose, segundo serovar reagente, título de aglutininas e momento da colheita de sangue

\begin{tabular}{lcccccc}
\hline & \multicolumn{3}{c}{ Março 2006 } & \multicolumn{3}{c}{ Maio 2007 } \\
\hline Bratislava & $\mathbf{8 0 0}$ & $\mathbf{2 0 0} \mathbf{e}<\mathbf{4 0 0}$ & TOTAL & $\mathbf{2 8 0 0}$ & $\mathbf{2 0 0}$ e $<\mathbf{4 0 0}$ & TOTAL \\
Icterohaemorrhagiae & 37 & 35 & 72 & 2 & 7 & 9 \\
Australis & 2 & 4 & 6 & - & 2 & 2 \\
Reativos & 1 & 3 & 4 & - & - & - \\
Não-reativos & 40 & 42 & $82(55,4 \%)$ & 2 & 9 & $11(35,5 \%)$ \\
\hline TOTAL & - & - & 66 & - & - & 20 \\
\hline
\end{tabular}

Diante dos achados e da caracterização do surto de leptospirose com sorologia predominante para o serovar Bratislava, um amplo programa de controle foi implementado, incluindo abordagens vacinais, medicamentosas e epidemiológicas. No que se refere a medidas vacinais, todos os animais do plantel foram vacinados; já a antibioticoterapia foi aplicada apenas nos animais com títulos $\geq 200$, conforme descrito.

No segundo momento do estudo, realizado 12 meses após a implementação do programa de controle (maio de 2007), os animais foram submetidos a nova avaliação clínica e reprodutiva, de acordo com a análise de fichas individuais. Nesta ocasião, a análise dos parâmetros reprodutivos revelou redução no índice de abortamento de $12 \%$ para $4 \%$, da morte embrionária de $10 \%$ para $2 \%$ e da morte neonatal de $8 \%$ para $1 \%$, totalizando $7 \%$ de prejuízos reprodutivos, perante os $30 \%$ observados antes da implementação do programa de controle. Os fetos abortados verificados no período não mais apresentavam sinais de icterícia, hepatomegalia ou fígados friáveis. No que se refere à incidência de uveíte, esta caiu de 16 para dois casos, considerando-se os 12 meses anteriores (Tabela 2).

Tabela 2: Eqüinos de propriedade do estado do Rio de janeiro, Brasil, onde foi aplicado programa de controle da leptospirose segundo o momento do exame clínico e a freqüência de transtornos reprodutivos

\begin{tabular}{lcc}
\hline & Março 2006 & Maio 2007 \\
\hline \% Morte neonatal & 8 & 1 \\
\% Morte embrionária & 10 & 2 \\
\% Abortamento & 12 & 4 \\
\% Prejuízos reprodutivos & 30 & 7 \\
Uveítes (novos casos) & 16 & 2 \\
\hline
\end{tabular}

Nesta ocasião, selecionaram-se randomicamente 31 fêmeas para testagem sorológica. Somente dois animais $(6,4 \%)$ apresentaram títulos $\geq 800$ enquanto nove (29\%) tinham títulos entre 200 e 400. Em relação à distribuição do serovar infectante, sv. Bratislava foi mais uma vez o mais freqüente, tendo sido identificado nas duas amostras com altos títulos e em sete das nove fracamente reativas, totalizando nove $(81,8 \%)$ amostras com títulos $\geq 200$. O sv. Icterohaemorrhagiae também foi observado, correspondendo a duas $(18,2 \%)$ das amostras com títulos $\geq 200$.

\section{Discussão}

Apesar dos sv. Pomona e Icterohaemorrhagiae serem os mais freqüentemente associados a sinais clínicos agudos e à ocorrência de surtos de leptospirose em eqüinos, o papel do sv. Bratislava vem sendo cada vez mais reconhecido na etiologia desta infecção, com importantes prejuízos, em especial na esfera reprodutiva (Faine et al., 2000; Pinna et al., 2007).

Este serovar é mantido pelo próprio hospedeiro eqüino, podendo determinar alterações reprodutivas (Donahue et al., 1995) e, mais freqüentemente, casos de infecção subclínica (Ellis et al., 1983; Faine et al., 2000). Apesar de apresentar uma soroprevalência variável de acordo com a região do mundo, este sv. vem sendo pouco descrito no Brasil, onde ainda predomina a infecção pelo sv. Icterohaemorrhagiae (Lilenbaum, 1998; Vasconcellos, 2000; Pescador et al., 2004). Acredita-se que a ocorrência deste surto deva-se, portanto, ao somatório de algumas situações particulares; por um lado, a presença de um eficiente programa de controle de roedores, reservatórios naturais do sv. Icterohaemorrhagiae permitiu que a ocorrência de casos agudos de leptospirose determinada por este serovar, sabidamente o mais freqüente no Brasil, tenha sido bastante reduzido. Deve-se notar que, apesar de não mais predominante, alguns animais ainda apresentavam sororreatividade para esta amostra, o que confirma sua presença neste plantel, ainda que controlado.

Por outro lado, o ingresso freqüente de animais oriundos de diferentes haras de diversas regiões do país, sem a devida comprovação de soronegatividade para leptospirose ou sem cumprir um período de quarentena, associado a características ambientais, como a presença de alagadiços e do lago para exercícios, permitiu a disseminação e manutenção da infecção pelo sv. Bratislava. Uma vez que este serovar é mantido pelo próprio eqüino (Donahue et al., 1995), a fonte de infecção mais provável tenha sido um animal infectado oriundo de outro haras, visto o grande número de 
animais ingressantes no plantel, sem o devido controle. Assim, não há necessidade de outros reservatórios animais para sua disseminação; entretanto, a presença de fatores ambientais favoráveis a sua transmissão, em especial aqueles relacionados com alagadiços e ao lago de exercícios, foram fundamentais para a abrangência do surto neste plantel.

O uso de bacterinas como medida preventiva da leptospirose em eqüinos é controverso (Donahue et al., 1995). Devido ao grande número de transtornos reprodutivos associados à leptospirose nesta espécie, vários artigos citam o uso de vacinas licenciadas para uso em bovinos, com resultados variáveis. Apesar de induzirem altos títulos protetores, sua real eficiência nesta espécie ainda é desconhecida (Heath e Johnson, 1994), sem considerar a possível ocorrência de rações anafiláticas após seu uso.

Poucos são os programas de controle de leptospirose que enfatizam a adoção do controle ambiental associado à tradicional combinação de vacinação e antibioticoterapia. No entanto, sabe-se que manejo e ambiente influenciam na transmissão da infecção em diversas espécies, tais como

\section{Referências}

ALONSO-ANDICOBERRY C., GARCIA-PENA, F.J., PEREIRA-BUENO, J., COSTAS, E., ORTEGA-MORA, L.M. Herd-level risk factors associated with Leptospira spp. Seroprevalence in dairy and beef cattle in Spain. Preventive Veterinary Medicine v. 52, p.109-117, 2001.

BOQVIST, S.; THU, H.T.V.; VAGSHOLM, I.; MAGNUSSON, U. The impact of Leptospira seropositivity on reproductive performance in sows in southern Viet Nam. Theriogenology, v. 58, p. 1327-35, 2002.

CORDEIRO, F.; RAMOS, A.A.; BATISTA, J.A. Aglutininas antileptospira em soros eqüinos de Minas Gerais. Pesquisa Agropecuária Brasileira. Série veterinária, v. 9, n. 7, p. 45-48, 1974.

CORREA, M.O.A.; AMATO NETO, V.; VERONESI, R.; FABBRI, O.S. Leptospiroses em eqüinos: Inquérito sorológico. Revista do Instituto Adolfo Lutz, v. 15, n. único, p. 186-193, 1955.

DONAHUE, J.M., SMITH, B.J., POONACHA, K.B., DONAHUE, J.K., RIGSBY, C.L. Prevalence and serovars of leptospira involved in equine abortions in central Kentucky during the 1991-1993 foaling seasons. Journal of Veterinary Diagnostic Investigation, v. 7, p. 87-91, 1995.

ELLIS, W.A., O'BRIEN, J.J., CASSELS, J.A., MONTGOMERY, J. Leptospiral infection in horses in Northern Ireland: Serological and microbiological findings. Equine Veterinary Journal, v. 15, p. 317-320, 1983.

FAINE, S., ADLER, B., BOLIN, C., PEROLAT, P. Leptospira and Leptospirosis. Australia: Medsci, 2000.272 p.

GERRITSEN, M.J., KOOPMANS, M.,DEKKER, T.G.E.M., DEJONG,M.C.M., MOERMAN, A., OLYHOCK, T. Effective treatment with dihydrostreptomycin of naturally infected cows shedding Leptospira interrogans serovar hardjo subtype hardjobovis. American Journal of Veterinary Research, v. 55, n. 3, March, 1994.

HEAT, S.E., JOHNSON, R. Leptospirosis. JAVMA, v. 205, p. 1518-1523, 1994. em suínos (Ramos e Lilenbaum, 2002; Boqvist et al., 2002), bovinos (Alonso-Andicoberry et al., 2001; Lilenbaum e Souza, 2003) e caprinos (Lilenbaum et al., 2008). Em todos estes estudos, apesar de conduzidos com diferentes espécies e conseqüentemente com outros serovares de leptospiras, observou-se que tais fatores interferem de forma marcante na distribuição da infecção leptospírica entre os rebanhos e mesmo entre os animais do mesmo rebanho. Assim, o presente estudo vem corroborar, como aplicação prática, esta missiva, associando o estudo e a correção de fatores ambientais que favoreçam a manutenção e a transmissão do agente às medidas tradicionais de controle da leptospirose em eqüinos, com resultados animadores.

Desta forma, conclui-se que a ampla abordagem, incluindo, simultaneamente, vacinação, antibioticoterapia e a administração de alguns aspectos ambientais, principalmente a interdição do lago para exercício dos animais, foi imprescindível para o sucesso no controle do surto. O presente estudo foi conduzido em área tropical e, acredita-se, possa contribuir para um melhor entendimento da epidemiologia da leptospirose em cavalos e mais especificamente aplicada à reprodução.

LEVETT, P.N. Leptospirosis. Clinical Microbiology Reviews. Apr, v. 14, n. 2, p. 296-326, 2001.

LILENBAUM, W., SANTOS, M.R.C. Effect of Management Systems on the prevalence of Bovine Leptospirosis. The Veterinary Record, v. 138, p. 570-571, 1995.

LILENBAUM, W. Leptospirosis on animal reproduction: IV. Serological findings in mares from six farms in Rio de Janeiro, Brazil (1993-1998). Braz. J. vet. Res. anim Sci. São Paulo, v. 35, n. 2, p. 61-63, 1998.

LILENBAUM, W., SOUZA, G.N.. Factors associated to bovine leptospirosis in Rio de Janeiro, Brazil. Research in Veterinary Science, v. 75, p. 249-251, 2003.

LILENBAUM, W., VARGES, R., MEDEIROS, L., CORDEIRO, A.G., CAVALCANTE, A., SOUZA, G.N., RICHTZENHAIN, L., VASCONCELLOS, S.A. Risk factors associated with leptospirosis in dairy goats under tropical conditions in Brazil. Research in Veterinary Science, v. 84, p. 14-17, 2008.

PESCADOR, C.A., CORBELLINI, L.G., LORETTI, A.P., WUNDER JR. E., FRANTZ, F.G., DRIEMEIER, D. Aborto eqüino por Leptospira sp. Ciência Rural, Santa Maria, v. 34, n. 1, p. 271-274, jan.-fev., 2004.

PINNA, M.H., VARGES, R., ABREU, R., LILENBAUM, W. Outbreak of equine leptospirosis by s. Bratislava. Online Journal of Veterinary Research., v. 11, n. 3, p. 1-4, 2007.

RAMOS, A.C.F., LILENBAUM, W. Fatores que influenciam na ocorrência de aglutininas anti-leptospira em suínos de criação tecnificada no Estado do Rio de Janeiro. Revista Brasileira de Medicina Veterinária, Rio de Janeiro, v. 24, n. 2, p. 78-80, 2002.

VASCONCELLOS, S.A. Leptospirose em animais domésticos e silvestres - prevenção e controle. Salvador: Oficina Estado da Arte e Prioridades para P\&D em Leptospirose/FIOCRUZ. 2000. 12 p. 